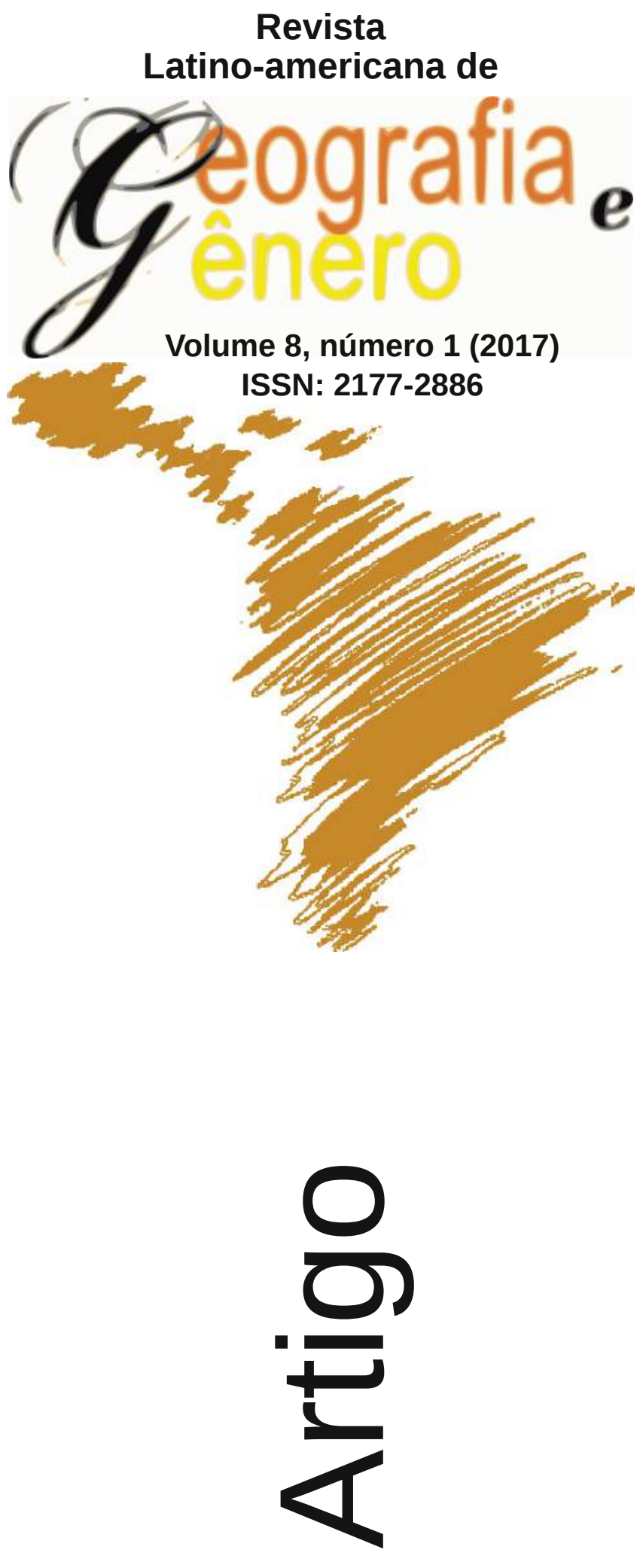

\title{
Transição Demográfica no Brasil e Planejamento da Parentalidade no Contexto da Bioética
}

Transición Demográfica en Brasil y Planificación

Familiar en el Contexto de la Bioética

Demographic Transition in Brazil and Parenthood Planning in the Context of Bioethics

Mário Antônio Sanches

Pontifícia Universidade Católica do Paraná - Brasil m.sanches@pucpr.br

Cleusa Regina Ferreira da Luz

Pontifícia Universidade Católica do Paraná - Brasil cleusa_ferreira@outlook.com.br

Daiane Priscila Simão-Silva

Pontifícia Universidade Católica do Paraná - Brasil dpscientist@gmail.com

Como citar este artigo:

SANCHES, Mário Antônio; LUZ, Cleusa Regina Ferreira da; SIMÂO-SILVA, Daiane Priscila. Transição Demográfica no Brasil e Planejamento da Parentalidade no Contexto da Bioética. Revista Latino Americana de Geografia e Gênero, v. 8, n. 1, p. 159-176, 2017. ISSN 2177-2886.

Disponível em:

http://www.revistas2.uepg.br/index.php/rlagg 


\section{Transição Demográfica no Brasil e Planejamento da Parentalidade no Contexto da Bioética}

\section{Transición Demográfica en Brasil y Planificación Familiar en el Contexto de la Bioética}

\section{Demographic Transition in Brazil and Parenthood Planning in the Context of Bioethics}

\section{Resumo}

O presente estudo objetiva analisar a terceira fase da transição demográfica no Brasil nas últimas décadas, por meio de resultados obtidos em pesquisa de campo realizada em Curitiba e Jacarezinho, no estado do Paraná. Os resultados obtidos confirmam os últimos censos, onde os indicadores demográficos utilizados apontam que a terceira fase da transição demográfica no Brasil foi percebida nas comunidades estudadas acompanhadas, também, de uma mudança do perfil socioeconômico da população, com destaque à mudança do papel da mulher. A problemática aqui apresentada justifica-se no campo da bioética por se entender que caracterizar a transição demográfica pode ajudar a pensar a estratégia de saúde da família e, mais especificamente, o planejamento familiar no país.

Palavras-Chave: Transição Demográfica; Parentalidade; Fecundidade; Estrutura Etária.

\section{Resumen}

Este estudio tiene como objetivo analizar la tercera fase de la transición demográfica en Brasil en las últimas décadas, a través de resultados obtenidos en la investigación de campo realizada en Curitiba y Jacarezinho, en el estado de Paraná. Los resultados obtenidos confirman los últimos censos, donde los indicadores demográficos utilizados apuntan que la tercera fase de la transición demográfica en Brasil se percibió en las comunidades estudiadas acompañadas también de un cambio del perfil socioeconómico de la población, destacando los cambios en el papel de las mujeres. La cuestión que se presenta aquí se justifica en el campo de la bioética ya que se entiende que caracterizar la transición demográfica puede ayudar a pensar la estrategia de salud de la familia y, más concretamente, la planificación familiar en el país.

Palabras-Clave: Transición Demográfica; Crianza; Fecundidad; Estructura de Edad.

\section{Abstract}

This study aims to analyze the third stage of demographic transition in Brazil, in recent decades, through results obtained from field researches held in Curitiba and Jacarezinho, State of Paraná, Brazil. The results confirm the last census, whose demographic indicators demonstrated that the third stage of demographic transition in Brazil was perceived in the communities studied, also accompanied by a change in the socio-economic profile of the population, with emphasis on the changing role of women. The problem presented here is justified in the field of bioethics by understanding that characterizing the demographic transition may help to think of the family health strategy and, more specifically, the family planning in the country.

Keywords: Demographic Transition; Parenting; Fecundity; Age Structure.

Mário Antônio Sanches, Cleusa Regina Ferreira da Luz, Daiane Priscila Simão-Silva 
Introdução

Esse artigo teve como objetivo geral analisar a terceira fase da transição demográfica que vem ocorrendo no Brasil por meio dos resultados de pesquisa de campo, tendo como objetivos específicos, relacionar os indicadores de parentalidade com a transição demográfica do Brasil e relacionar a mudança de padrão da fecundidade e da estrutura etária com os indicadores de parentalidade.

O presente estudo, com seus objetivos, está inserido no grupo de pesquisa ${ }^{1}$ que aborda a temática do 'Planejamento da Parentalidade', um tema usualmente compreendido como parte da ampla temática do planejamento familiar, aqui situado no âmbito da bioética. Planejar a parentalidade é necessário, principalmente neste início do século XXI, em que as famílias numerosas passam a serem vistas pela sociedade como um problema, sobretudo naquelas em que os pais não têm condições de acompanhar e educar todos os filhos, dentro da expectativa da sociedade.

A população brasileira presenciou, a partir de 1940, um declínio significativo da mortalidade, como consequência direta da transferência de tecnologias médico-sanitárias dos países desenvolvidos e da modernização econômica e social que começaria a ser implantada no país. Nas décadas seguintes, essas mudanças foram acompanhadas de um aumento no número de idosos e do declínio da fecundidade. Inicialmente, esse processo aconteceu nos grupos populacionais mais privilegiados economicamente e residentes nas regiões mais dinâmicas e produtivas do país, de forma que a transição demográfica é diferenciada entre grupos sociais (BRITO, 2008).

De 1960 a 2010, a expectativa de vida do brasileiro aumentou 25,4 anos, passando de 48,0 para 73,4 anos. Por outro lado, o número médio de filhos por mulher caiu de 6,3 filhos para 1,9 nesse mesmo período, valor abaixo do nível de reposição da população (IBGE, 2010). Essas mudanças alteraram a pirâmide etária, com estreitamento da base e o alargamento do topo, refletindo a estrutura de população mais envelhecida, característica dos países desenvolvidos e de uma redução da população jovem, o que poderá contribuir por melhorias na qualidade das políticas públicas destinadas a essa parcela da população, como argumenta Brito: 'No caso dos serviços relativos à população jovem, como os educacionais, a redução do ritmo de crescimento da demanda pode favorecer a universalização da cobertura e a melhoria da qualidade do ensino' (2008).

Situadas nesse contexto de transformações, crescem as famílias de casais sem filhos, como apontou o último censo do IBGE (2010), que 20,2\% das famílias eram formadas por casais sem filhos. Essa mudança no padrão familiar torna o projeto de parentalidade como elemento indispensável do planejamento familiar, como argumenta Sato (2013, p. 26): "Parentalidade não é apenas um projeto de crescimento e satisfação pessoal, pois a sua realização implica necessariamente na geração de vidas humanas".

1 Grupo de Pesquisa Teologia e Bioética, registrado no CNPq desde 2002, vinculado ao Programa de Pós-graduação em Bioética e ao Programa de Pós-graduação em Teologia, ambos da PUCPR.

Mário Antônio Sanches, Cleusa Regina Ferreira da Luz, Daiane Priscila Simão-Silva 
A problemática aqui apresentada justifica-se no campo da bioética por se entender que caracterizar a transição demográfica pode ajudar a pensar a estratégia de saúde da família e, mais especificamente, o planejamento familiar no país. Isso implica em uma abordagem ampla, aberta à contribuição de diversas áreas do conhecimento, já que se entende que o planejamento familiar não pode ser confundido com controle de natalidade, mas que precisa respeitar a autonomia do casal.

Percebe-se que a bioética tem-se afirmado como indispensável ao avanço da reflexão ética no âmbito das ciências da saúde e das ciências humanas, exatamente por promover o diálogo interdisciplinar. É possível aplicar essa reflexão interdisciplinar nas mudanças do comportamento populacional do país, uma vez que resulta de diferentes esferas e, principalmente, da modernização social e econômica das últimas décadas, como a inserção da mulher no mercado de trabalho e do acesso aos serviços de saúde, conforme argumenta Fortes: "A saúde pode potenciar o crescimento econômico de um país” (2003, p. 111).

\section{Metodologia}

Esse artigo resultou do referencial teórico a respeito do tema proposto - a transição demográfica no Brasil - como, também, da interpretação dos dados da pesquisa de campo sobre planejamento da parentalidade. Dessa forma, não é uma pesquisa longitudinal, mas busca associar os resultados dos últimos censos demográficos ao planejamento de parentalidade, identificando-se como uma pesquisa transversal.

Na pesquisa de campo foi aplicado o instrumento de pesquisa 'Planejamento da Parentalidade no Contexto da Bioética'2, que compreendeu 53 questões relacionadas ao planejamento familiar. Esse instrumento de pesquisa objetiva identificar as causas da ausência ou presença de projeto de parentalidade em pessoas que já tiveram filhos e busca relacionar com a sexualidade; modelos de família, questões sociais e religião, possibilitando análises diversas. Considerou apenas seis de um total de 53 questões que compreendem o questionário. Os descritores analisados, nesse caso, estão relacionados às questões demográficas e sociais pertinentes ao tema estudado.

A pesquisa foi realizada nos municípios de Curitiba e Jacarezinho, no estado do Paraná, no ano de 2015. No total, foram entrevistadas 655 pessoas, conforme informações da Tabela 1, em que está apresentado o perfil dos entrevistados por gênero e idade atual. A abordagem aos sujeitos da pesquisa ${ }^{3}$ ocorreu em eventos educacionais, religiosos ou sociais, organizados em comunidades da Igreja Católica, portanto, o perfil dos entrevistados caracteriza-se também por serem pessoas atuantes na Igreja.

A pesquisa abordou pessoas de diferentes faixas etárias, com $43,7 \%$ acima

2 Este instrumento de pesquisa - Planejamento de Parentalidade no Contexto da Bioética - foi elaborado e validado pelo Grupo de Pesquisa Teologia e Bioética da PUCPR em projeto de pesquisa de 2010 a julho de 2013 (SANCHES, et al, 2015).

3 O projeto foi submetido e aprovado pelo Comitê de Ética em Pesquisa da PUCPR, com parecer de número 409.841, na data de 25/09/2013.

Mário Antônio Sanches, Cleusa Regina Ferreira da Luz, Daiane Priscila Simão-Silva 
Transição Demográfica no Brasil e Planejamento da Parentalidade no

Contexto da Bioética

Tabela 1 -Perfil geral dos entrevistados por gênero e idade.

\begin{tabular}{|c|c|c|}
\hline & Percentagem & $\mathrm{N}^{0}$ de entrevistados \\
\hline \multicolumn{3}{|l|}{ Gênero } \\
\hline Masculino & $26,9 \%$ & 176 \\
\hline Feminino & $71,5 \%$ & 468 \\
\hline \multicolumn{3}{|l|}{ Idade atual } \\
\hline Entre 18 e 25 anos & $2,1 \%$ & 14 \\
\hline Entre 26 e 35 anos & $15,9 \%$ & 104 \\
\hline Entre 36 e 45 anos* & $35,4 \%$ & 232 \\
\hline Entre 46 e 60 anos* & $33,3 \%$ & 218 \\
\hline Acima de 60 anos & $10,4 \%$ & 68 \\
\hline
\end{tabular}

Nota: *faixa etária com predominância de mulheres

Fonte: Os autores (2015).

dos 46 anos. Dessa forma, a pesquisa não dá um recorte atual, pois uma pessoa acima de 60 anos pode ter tido sua primeira gravidez há cerca de 45 anos, que será analisado dentro desse contexto. Assim, esse estudo permite visualizar um quadro da situação nas últimas décadas, em que buscou refletir sobre os dados que estão relacionados à transição demográfica.

A partir dos dados coletados na pesquisa de campo, foi feita análise com o programa SPSS Statistics, versão 22.0. Na construção das tabelas, foi utilizada a estatística descritiva. Para a análise de correlação, foi utilizado o teste de Correlação de Spearman e o teste de Qui-quadrado $\left(\mathrm{X}^{2}\right)$ para comparação das variáveis categóricas. Considerou-se como significativo os valores de $p$ menores que 0,05 .

\section{Transição Demográfica}

Adolphe Landry propôs, em 1934, a teoria da transição demográfica, baseada na observação da evolução das populações europeias. Essa teoria afirma que as populações passam por profundas transformações econômicas e sociais, de um equilíbrio entre alta fecundidade e alta mortalidade, a um equilíbrio entre baixa fecundidade e baixa mortalidade, em certa etapa de sua história. Segundo Bandeira (1996, p. 14):

Quando Landry escreveu Lestroistheories de lapopulation, a população francesa constituía um problema, que era o risco de despovoamento, manifestado pela ausência de crescimento natural, devido à baixíssima taxa de reprodução e consequente envelhecimento.

A teoria da transição demográfica fundamenta-se em uma observação nas

Mário Antônio Sanches, Cleusa Regina Ferreira da Luz, Daiane Priscila Simão-Silva 
três fases do desenvolvimento pelas quais passaram as populações industrializadas. Na primeira fase, que corresponderia à fase pré-industrial, ocorrem altas e estabilizadas taxas de natalidade e mortalidade. Na segunda, que se refere ao período industrial, a taxa de natalidade permanece alta, enquanto a de mortalidade encontra-se em constante declínio, como consequência de melhorias na nutrição, saúde e saneamento básico. Essa etapa caracteriza-se, sobretudo, por um forte crescimento demográfico e pela diminuição da mortalidade.

A terceira fase da transição demográfica, pós-industrial, reflete em taxas de natalidade e mortalidade baixas e equilibradas, em que nascem menos filhos e sobrevivem mais que na primeira fase. Em alguns países, contudo, a taxa de natalidade tem declinado, tanto que está ocasionando uma redução na população, como na Alemanha e em outros países europeus. O Brasil entrou nessa fase a partir da década de 1960, quando iniciou o declínio na fecundidade, como cita Brito (2008), de que "no caso brasileiro, as transições de mortalidade e fecundidade já estão adiantadas e estamos passando, atualmente, pela terceira fase da transição demográfica".

É necessário que se considere um longo período de tempo para passar de uma fase a outra, uma vez que o crescimento populacional vai moldando-se às novas transformações sociais e econômicas que se desenrolam na sociedade.

A transição demográfica leva décadas. A princípio, isso coloca problemas diante da perspectiva temporal dos formuladores de políticas públicas, que normalmente planejam considerando um período muito inferior (BRITO, 2008, p. 6).

As transformações econômicas e sociais necessárias para que se verifique o processo de alteração da teoria da transição demográfica envolvem: um maior crescimento econômico, com progressos na produção e distribuição de alimentos, melhorias na nutrição, crescimento industrial, progresso médico e sanitário, controle da mortalidade e fecundidade, popularização de anticoncepcionais, a evolução cultural, aumento do nível de vida e, principalmente, da mentalidade das populações. Como pontua Bandeira (1996, p. 19), "Essas mudanças resultam em primeiro lugar das transformações das antigas formas de organização familiar". Mudanças essas que recebem influência da modernização política e econômica no processo de desenvolvimento dos países e alteram suas estruturas. "O objetivo social de perpetuar a família cedeu progressivamente ao lugar de promover a saúde, a educação e o bem-estar material do indivíduo criança".

A transição demográfica dá-se em épocas e ritmos diferentes, nos países em desenvolvimento. Naqueles que ainda apresentam elevado crescimento populacional, a transição pode ser tornar uma realidade. Contudo, apresenta características diferentes, como argumenta Brito (2008, p. 7): "A transição demográfica nos países em desenvolvimento, latino-americanos e asiáticos, tem sido muito mais acelerada do que naqueles desenvolvidos". As taxas de mortalidade desses países diminuíram drasticamente nos anos 1970, como resultado das intervenções médicas e sanitárias, contudo não se produzia um declínio paralelo da fecundidade.

Mário Antônio Sanches, Cleusa Regina Ferreira da Luz, Daiane Priscila Simão-Silva 
Alguns países em desenvolvimento, com elevado crescimento, passaram por políticas explicitamente antinatalistas, por ter permanecido longo tempo na segunda fase da transição, caracterizada por um acelerado crescimento populacional. Segundo Puyol (1992, p. 132), "Tudo parece indicar que a maior rapidez na redução da mortalidade nos países subdesenvolvidos, se pode compensar com uma maior aceleração na redução da natalidade". Algumas medidas de saúde pública são aplicadas em certos países de forma acelerada, sem dar tempo das populações adaptarem-se. Além disso, entram em jogo os padrões religiosos e culturais que, por sua natureza, requerem normalmente períodos longos de tempo para que as mudanças realmente ocorram.

\section{Declínio da Fecundidade}

A partir da década de 1970, o Brasil começou a apresentar redução dos seus níveis de crescimento populacional. Em 1970, a taxa de fecundidade total era de 5,76; em 1980, de 4,36; em 1990, caiu para 2,79 filhos; em 2000, a taxa de fecundidade continuou a declinar, atingindo 2,4 e em 2010 atingiu 1,9 filho por mulher (IBGE, 2010). Esse declínio pode ser atribuído às transformações sociais, concentração urbana, evolução nas condições de saúde e educação e popularização dos métodos contraceptivos. O declínio da fecundidade colocou o país na terceira fase da transição demográfica. Essa queda na taxa de fecundidade demonstra mudanças no comportamento demográfico e transformações culturais que modificam o papel funcional atribuído às mulheres.

Conforme dados apresentados na Tabela 2, observam-se fortes desequilíbrios regionais e por consequências sociais na redução da fecundidade de 1970 a 2010. Essa diferença regional resulta, também, da disparidade no nível educacional e de saúde. Conforme dados do IBGE (2010), “entre as mulheres sem instrução e com ensino fundamental incompleto, a taxa de fecundidade chega a 3,09 filhos por mulher, enquanto que, no outro extremo (mulheres com ensino superior completo), a taxa é de 1,14 filho".

Tabela 2 - Taxa de fecundidade total, segundo as grandes regiões - 1970/2000 e 2010.

\begin{tabular}{|c|c|c|c|}
\hline Grandes Regiões & $\mathbf{1 9 7 0}$ & $\mathbf{2 0 0 0}$ & $\mathbf{2 0 1 0}$ \\
\hline Brasil & 5,76 & 2,38 & 1,90 \\
\hline Norte & 8,15 & 3,16 & 2,47 \\
\hline Nordeste & 7,53 & 2,69 & 2,06 \\
\hline Sudeste & 4,56 & 2,10 & 1,70 \\
\hline Sul & 5,42 & 2,24 & 1,78 \\
\hline Centro-Oeste & 6,42 & 2,25 & 1,92 \\
\hline
\end{tabular}

Fonte: IBGE, Censos Demográficos de 1970, 2000 e 2010.

Ao considerar a série de censos brasileiros, observa-se que a população vem experimentando sucessivos aumentos em seu contingente, embora a velocidade

Mário Antônio Sanches, Cleusa Regina Ferreira da Luz, Daiane Priscila Simão-Silva 
desse crescimento venha diminuindo progressivamente nas últimas décadas, refletindo a continuidade do declínio da fecundidade, como argumenta Silva $(2000, \mathrm{~s} / \mathrm{p})$.

Entendemos que a regulação da fecundidade e a consequente adoção de uma prática anticonceptiva correlaciona-se com o processo de expansão urbano-industrial e suas consequências socioculturais, as quais possibilitam mudanças comportamentais em relação à prática reprodutiva.

A partir dos resultados apresentados na Tabela 3, observa-se a quantidade de filhos por faixa etária, o que torna possível relacionar com o projeto de parentalidade. Quando comparadas as faixas etárias de 36-45 e 46-60, foi constatado um predomínio de dois filhos, que chega a 48,7\% e 38,5\%, respectivamente, o que corrobora com a terceira fase da transição demográfica, caracterizada com a redução da fertilidade.

Tabela 3 - Dados relacionados com "idade atual dos entrevistados" cruzados com a "número de filhos"

\begin{tabular}{|c|c|c|c|c|c|c|c|}
\hline & & \multicolumn{5}{|c|}{ Número de filhos } & \multirow{2}{*}{ Total } \\
\cline { 1 - 6 } Idade & & $\mathbf{1}$ filho & $\mathbf{2}$ filho & $\mathbf{3}$ filho & $\mathbf{4}$ ou + & NR & \\
\hline Entre & $\mathrm{N}$ & 11 & 1 & 2 & 0 & 0 & 14 \\
\hline 18 e 25 & $\%$ & $78,6 \%$ & $7,1 \%$ & $14,3 \%$ & $0,0 \%$ & $0,0 \%$ & $100,0 \%$ \\
\hline Entre & $\mathrm{N}$ & 45 & 33 & 24 & 0 & 2 & 104 \\
\hline 26 e 35 & $\%$ & $43,3 \%$ & $31,7 \%$ & $23,1 \%$ & $0,0 \%$ & $1,9 \%$ & $100,0 \%$ \\
\hline Entre & $\mathrm{N}$ & 55 & 113 & 54 & 9 & 1 & 232 \\
\hline 36 e 45 & $\%$ & $23,7 \%$ & $48,7 \%$ & $23,3 \%$ & $3,9 \%$ & $0,4 \%$ & $100,0 \%$ \\
\hline Entre & $\mathrm{N}$ & 33 & 84 & 68 & 30 & 3 & 218 \\
\hline 46 e 60 & $\%$ & $15,1 \%$ & $38,5 \%$ & $31,2 \%$ & $13,8 \%$ & $1,4 \%$ & $100,0 \%$ \\
\hline Acima & $\mathrm{N}$ & 5 & 26 & 15 & 18 & 4 & 68 \\
\hline De 60 & $\%$ & $7,4 \%$ & $38,2 \%$ & $22,1 \%$ & $26,5 \%$ & $5,9 \%$ & $100,0 \%$ \\
\hline NR & $\mathrm{N}$ & 5 & 12 & 2 & 0 & 0 & 19 \\
\hline & $\%$ & $26,3 \%$ & $63,2 \%$ & $10,5 \%$ & $0,0 \%$ & $0,0 \%$ & $100,0 \%$ \\
\hline Total & $\mathrm{N}$ & 154 & 169 & 165 & 57 & 10 & 655 \\
\hline & $\%$ & $23,5 \%$ & $41,1 \%$ & $25,2 \%$ & $8,7 \%$ & $1,5 \%$ & $100,0 \%$ \\
\hline
\end{tabular}

Fonte: Os autores (2015). 
O predomínio de um filho entre os mais jovens, de 18-25 e 26-35 anos, corrobora com a percepção de casamentos tardios e do planejamento de parentalidade. Nos dados apresentados na Tabela 3, houve correlação positiva entre a idade atual do entrevistado com o número de filhos, quanto maior a faixa etária, maior o número de filhos $(\mathrm{r}=0,287 ; \mathrm{p}=0,00)$.

\section{Alteração na Estrutura Etária}

Como foi citado, nas últimas décadas, presenciou-se alteração na estrutura etária da população brasileira, como consequência das mudanças ocorridas na demografia, que se iniciou por meio de um rápido declínio nos níveis de mortalidade após a Segunda Guerra Mundial, seguido pela diminuição dos níveis de fecundidade, desde os anos 1970. Essa mudança no padrão demográfico indicou que o país situa-se numa fase de transição que constitui uma das mais importantes transformações da sociedade brasileira, o que gerou consequências em todos os setores, tanto públicos quanto privados. Assim, o crescimento populacional esteve em constante declínio, já que em 1991 era de $1,93 \%$, no início do século XXI foi de $1,64 \%$ e em 2010 encontrava-se em $1,17 \%$, com uma população total de aproximadamente 191 milhões de habitantes (IBGE, 2010).

O declínio nas taxas de mortalidade e fecundidade expressa o adensamento no padrão de envelhecimento da população brasileira, conforme Tabela 4. No Brasil, a transição demográfica teve início a partir da década de 1970. "As taxas sofreram redução de $24,1 \%$ entre 1970 e 1980, de 38,6\% na década seguinte e a partir daí, 11,1\% entre 1991 e 2000" (BERQUÓ; CAVENAGUI, 2006).

Tabela 4 - Brasil: Distribuição etária proporcional (\%), por grandes grupos etários, da população enumerada em 1970, 2000 e 2010.

\begin{tabular}{|c|c|c|c|}
\hline Grandes Regiões & $\mathbf{1 9 7 0}$ & $\mathbf{2 0 0 0}$ & $\mathbf{2 0 1 0}$ \\
\hline Brasil & 5,76 & 2,38 & 1,90 \\
\hline Norte & 8,15 & 3,16 & 2,47 \\
\hline Nordeste & 7,53 & 2,69 & 2,06 \\
\hline Sudeste & 4,56 & 2,10 & 1,70 \\
\hline Sul & 5,42 & 2,24 & 1,78 \\
\hline Centro-Oeste & 6,42 & 2,25 & 1,92 \\
\hline
\end{tabular}

Fonte: IBGE, Censos Demográficos de 1970, 2000 e 2010.

A partir dos dados apresentados, observa-se uma redução da população no grupo etário de 0 a 14 . Esse grupo teve uma redução de percentual populacional de $42,1 \%$ em 1970 para $24,1 \%$ em 2010, o que se percebe fortemente como resultado do declínio da fecundidade. Porém, na década de 1970, as taxas de fecundidade eram mais elevadas, com isso ocorreu um aumento da população em idade ativa (15 a 59 anos), de 52,8\% em 1970 para $68,5 \%$, em 2010. Também ocorreu um aumento na participação da população

Mário Antônio Sanches, Cleusa Regina Ferreira da Luz, Daiane Priscila Simão-Silva 


\section{Contexto da Bioética}

acima de 60 anos, que subiu de 5,1\% para 7,4\%.

Os dados coletados na pesquisa de campo permitiram relacionar as alterações demográficas na estrutura etária com as condições de empregabilidade na gravidez do primeiro filho. Na Tabela 5, é possível verificar a relação entre a questão: Qual era a sua situação de emprego na gravidez do primeiro filho? Com a questão que solicitava o "número de filhos". Houve correlação significativa entre o número de filhos e a situação de emprego na gravidez do primeiro filho $(\mathrm{r}=0,211 ; \mathrm{p}=0,00)$, com uma diferença significativa no número de filhos entre os que estavam empregados na gravidez do primeiro filho em relação aos que estavam no lar.

Tabela 5 - Dados relacionados com 'Situação de emprego na gravidez do primeiro filho' cruzados com 'número de filhos'

\begin{tabular}{|c|c|c|c|c|c|c|c|}
\hline & & \multicolumn{5}{|c|}{ Número de filhos } & \multirow{2}{*}{ Total } \\
\cline { 1 - 6 } $\begin{array}{c}\text { Situação de } \\
\text { Emprego }\end{array}$ & & $\mathbf{1}$ filho & $\mathbf{2}$ filho & $\mathbf{3}$ filho & $\mathbf{4}$ ou + & NR & \\
\hline Empregado & $\mathrm{N}$ & 99 & 175 & 80 & 13 & 4 & 371 \\
\hline & $\%$ & $26,7 \%$ & $47,2 \%$ & $21,6 \%$ & $3,5 \%$ & $1,1 \%$ & $100,0 \%$ \\
\hline Desempregado & $\mathrm{N}$ & 8 & 13 & 12 & 1 & 0 & 34 \\
\hline & $\%$ & $23,5 \%$ & $38,2 \%$ & $35,3 \%$ & $2,9 \%$ & $0,0 \%$ & $100,0 \%$ \\
\hline Autônomo & $\mathrm{N}$ & 13 & 30 & 31 & 5 & 1 & 80 \\
\hline Do lar & $\%$ & $16,3 \%$ & $37,5 \%$ & $38,8 \%$ & $6,3 \%$ & $1,3 \%$ & $100,0 \%$ \\
\hline & $\mathrm{N}$ & 26 & 44 & 39 & 36 & 5 & 150 \\
\hline Outro & $\mathrm{N}$ & 4 & 4 & 2 & 0 & 0 & 10 \\
\hline & $\%$ & $40,0 \%$ & $40,0 \%$ & $20,0 \%$ & $0,0 \%$ & $0,0 \%$ & $100,0 \%$ \\
\hline Total & $\mathrm{N}$ & 154 & 169 & 165 & 57 & 10 & 655 \\
\hline & $\mathrm{N}$ & 4 & 3 & 1 & 2 & 0 & 10 \\
\hline & $\%$ & $40,0 \%$ & $30,0 \%$ & $10,0 \%$ & $20,0 \%$ & $0,0 \%$ & $100,0 \%$ \\
\hline & $23,5 \%$ & $41,1 \%$ & $25,2 \%$ & $8,7 \%$ & $1,5 \%$ & $100,0 \%$ \\
\hline
\end{tabular}

Fonte: Os autores (2015).

A partir dos dados coletados, observa-se um predomínio acima de $70 \%$ dos entrevistados que estavam empregados na gravidez do primeiro filho, com um ou dois filhos. Essa tabela precisa ser bem compreendida, pois a questão apenas capta a situação de empregabilidade na gravidez do primeiro filho, situação esta que pode ter mudado nas gravidezes subsequentes e ao longo da vida. De qualquer modo, aponta para dados curiosos, como o fato de que 
apenas 3,5\% das pessoas que estavam empregadas na gravidez do primeiro filho chegaram a ter quatro filhos ou mais, contrapondo ao fato de que $24 \%$ que indicaram a situação de 'do lar' na gravidez do primeiro chegaram a ter quatro filhos. Isso pode representar a relação entre a participação continuada da mulher no mercado de trabalho com número de filhos.

Essa pesquisa pode indicar que a transição demográfica foi acompanhada, como causa ou consequência, de uma transformação socioeconômica da população. Desse modo, a tabela demonstra claramente o movimento de 'mais emprego menor número de filhos' e a situação inversa na questão de número de filhos comparados com a variável 'do lar', que precisa ser analisada em conjunto com outros dados da Tabela 6 , na qual a situação de emprego na gravidez do primeiro filho é cruzada com a idade dos entrevistados. Nessa tabela, as faixas etárias diferiram significativamente entre $26-35$ e $46-60\left(\mathrm{x}^{2}=\right.$ $4,25 ; \rho=0,04)$ e entre as faixas etárias de 36-45 com 46-60 $\left(x^{2}=10,15 ; \rho=\right.$ $0,00)$.

As porcentagens de pessoas com quatro ou mais filhos era maior entre as pessoas acima de 60 anos, ou seja, há uma relação entre 'situação de emprego na gravidez do primeiro filho e ter menos filhos' ou há uma situação diferenciada entre 'ter engravidado na década de 1970 ou ter engravidado na década de 2000'?

A porcentagem de pessoas que estavam empregadas na gravidez do primeiro filho não mudou ao longo dessas décadas. Desconsiderando a faixa etária entre 18 e 25 anos, por causa do pequeno número de participantes na pesquisa, pode-se ver claramente que a porcentagem que indica "do lar" na gravidez do primeiro filho cai significativa e continuamente conforme diminui a idade dos entrevistados. Na verdade, a porcentagem cai pela metade comparando as pessoas na faixa etária acima de 60 anos para as pessoas na faixa etária entre 26 e 35.

A análise das Tabelas 5 e 6 pode mostrar que a transição demográfica no Brasil foi percebida nas comunidades estudadas, acompanhada também de uma mudança do perfil socioeconômico da população, com destaque para a mudança do papel da mulher, pois sua participação tem sido cada vez mais efetiva na economia e nos meios culturais. "Esta transformação, tanto no interior da família como na sociedade, que torna exigente o debate sobre a libertação da mulher, enquanto ser humano e sujeito de direitos" (SATO, 2013, p. 48).

Tabela 6 - Dados relacionados com 'Situação de emprego na gravidez do primeiro filho' cruzados com 'Idade atual do entrevistado'

\begin{tabular}{|c|c|c|c|c|c|c|c|c|}
\hline & & \multicolumn{5}{|c|}{ Situação de emprego na gravidez do primeiro filho } & \multirow{2}{*}{ Total } \\
\cline { 1 - 7 } $\begin{array}{c}\text { Idade } \\
\text { Atual }\end{array}$ & & Empregado/a & Desempregado/a & Autônomo/a & Do lar & Outro & NR & \\
\hline Entre & $\mathrm{N}$ & 8 & 0 & 1 & 4 & 0 & 1 & 14 \\
\hline 18 e 25 & $\%$ & $57,1 \%$ & $0,0 \%$ & $7,1 \%$ & $28,6 \%$ & $0,0 \%$ & $7,1 \%$ & $100,0 \%$ \\
\hline Entre & $\mathrm{N}$ & 57 & 15 & 10 & 17 & 5 & 0 & 104 \\
\hline 26 e 35 & $\%$ & $54,8 \%$ & $14,4 \%$ & $9,6 \%$ & $16,3 \%$ & $4,8 \%$ & $0,0 \%$ & $100,0 \%$ \\
\hline
\end{tabular}

Mário Antônio Sanches, Cleusa Regina Ferreira da Luz, Daiane Priscila Simão-Silva 
Transição Demográfica no Brasil e Planejamento da Parentalidade no

Contexto da Bioética

\begin{tabular}{|c|c|c|c|c|c|c|c|c|}
\hline Entre & $\mathrm{N}$ & 151 & 13 & 24 & 41 & 3 & 0 & 232 \\
\hline 36 e 45 & $\%$ & $65,1 \%$ & $5,6 \%$ & $10,3 \%$ & $17,7 \%$ & $1,3 \%$ & $0,0 \%$ & $100,0 \%$ \\
\hline Entre & $\mathrm{N}$ & 114 & 4 & 32 & 65 & 1 & 2 & 218 \\
\hline 46 e 60 & $\%$ & $52,3 \%$ & $1,8 \%$ & $14,7 \%$ & $29,8 \%$ & $0,5 \%$ & $0,9 \%$ & $100,0 \%$ \\
\hline Acima & $\mathrm{N}$ & 29 & 2 & 8 & 22 & 1 & 6 & 68 \\
\hline De 60 & $\%$ & $42,6 \%$ & $2,9 \%$ & $11,8 \%$ & $32,4 \%$ & $1,5 \%$ & $8,8 \%$ & $100,0 \%$ \\
\hline NR & $\mathrm{N}$ & 12 & 0 & 5 & 1 & 0 & 1 & 19 \\
\hline & $\%$ & $63,2 \%$ & $0,0 \%$ & $26,3 \%$ & $5,3 \%$ & $0,0 \%$ & $5,3 \%$ & $100,0 \%$ \\
\hline Total & $\mathrm{N}$ & 371 & 34 & 80 & 150 & 10 & 10 & 655 \\
\hline & $\%$ & $56,6 \%$ & $5,2 \%$ & $12,2 \%$ & $22,9 \%$ & $1,5 \%$ & $1,5 \%$ & $100,0 \%$ \\
\hline
\end{tabular}

Fonte: Os autores (2014).

Essa mudança no papel da mulher refletiu nas mudanças no modo de vida das famílias brasileiras e observou-se uma queda no número de filhos. Esse declínio pode ser atribuído também à evolução nas condições de saúde e de educação e na popularização dos métodos contraceptivos, que desencadeiam alterações no núcleo familiar. A família, conforme Oliveira e Simões (2005, $\mathrm{s} / \mathrm{p}$ ): “deve ser uma referência central na formulação de políticas públicas de combate às desigualdades sociais no país e que a política de proteção à família é uma forma eficaz de atuar sobre a realidade de seus membros".

A urbanização acelerou a divulgação tanto no uso dos métodos contraceptivos quanto no modelo cultural vigente. Também os novos arranjos familiares, como se verificou no último censo, tiveram um aumento na proporção de famílias sob a responsabilidade exclusiva da mulher de $22,2 \%$, em 2000, contra 37,3\% em 2010 (IBGE, 2010). O percentual de famílias compostas por casais com filhos é superior na área rural, em função das taxas de fecundidade historicamente mais elevadas e, também, devido a valores culturais mais tradicionais. Observa-se, ainda, nas áreas rurais, um percentual consideravelmente inferior de famílias monoparentais femininas: 9,1\% contra 17,4\% nas áreas urbanas (IBGE, 2010).

Portanto, vive-se uma época de mudança no cenário do comportamento populacional, como cita Camarano (2013, p. 605):

O paradigma demográfico atual é bastante diferente do observado nos anos 1950: proliferação de famílias de filho único e de casais sem filhos; esperança de vida ao nascer e nas idades avançadas em rápido crescimento; diminuição do ritmo de crescimento da população; redução da força de trabalho; e envelhecimento.

Tudo isso remete às atuais mudanças demográficas dessa época, que exigem novas discussões e entrelaçamentos.

\section{Planejamento Familiar}

Na década de 1980, com a retomada da trajetória democrática no país, as Mário Antônio Sanches, Cleusa Regina Ferreira da Luz, Daiane Priscila Simão-Silva 
mulheres passaram a apropriar-se de certos direitos relacionados às suas escolhas, como no campo do planejamento familiar. Também os baixos níveis de fecundidade colaboraram com a popularização do planejamento familiar no país, o que indicou a disseminação de métodos contraceptivos. Nisso confirma Silva (2000, s/p): "a queda brusca da taxa de fecundidade no País, a partir da década de sessenta, indica o crescimento da adoção de procedimentos anticonceptivos". A pergunta que se faz é: o declínio populacional é fruto de fato de um melhor planejamento familiar no país? Ou o declínio da taxa de natalidade deu-se mesmo sem que a população assumisse conscientemente o planejamento familiar?

O planejamento familiar consolidou-se na Lei 9.263/96, quando no seu art. $1^{\circ}$ enfoca ser direito de todo cidadão e no art. $2^{\circ}$ destaca um conjunto de ações de regulação da fecundidade, que garanta direitos iguais de constituição, limitação ou aumento da prole pela mulher, pelo homem ou pelo casal (BRASIL, 2011). Essa lei incorpora muito do que havia sido discutido no país sobre o planejamento familiar enquanto um direito da mulher, do homem e do casal e mantém a abrangência de sua ação de responsabilidade no Sistema Único de Saúde em todos os seus níveis. É nesse contexto que se indaga sobre questões que precisam ser mais bem exploradas, pois a diminuição da taxa de fecundidade dá-se num ambiente de desigualdade social que precisa ser relacionado. Desse modo, essa diminuição é fruto de 'planejamento familiar' ou que se tem conseguido no Brasil é de fato 'controle demográfico'? Exatamente o que se pretendia evitar no artigo 2 da referida lei:

Art. $2^{\circ}$ : Para fins desta Lei entende-se planejamento familiar como o conjunto de ações de regulação da fecundidade que garanta direitos iguais de constituição, limitação ou aumento da prole pela mulher, pelo homem ou pelo casal.

Parágrafo único - É proibida a utilização das ações a que se refere o caput para qualquer tipo de controle demográfico.

Para esse debate, é necessário trazer as questões sociais e as transformações pelas quais passa a família no Brasil. Constata-se que a maioria da população jovem, no Brasil, é pobre, como mostram dados dos dois últimos censos, já que a porcentagem de jovens de família com renda domiciliar per capita inferior a um salário mínimo tem diminuído, mas situava-se, no ano 2000, acima de 70\%, mais de 32 milhões de pessoas e em 2010, cerca de 24 milhões de jovens (IBGE, 2010).

O aumento do percentual da população acima de 60 anos poderá nortear as políticas públicas e recursos que venham contemplar a sustentação, em níveis dignos, da crescente proporção dessa faixa etária. Como argumenta Berquó e Cavenagui (2006, p. 11):

Os níveis de fecundidade de um país fazem parte de um elenco de indicadores que orientam os formuladores de políticas públicas, dadas às implicações que taxas abaixo do nível de reposição (número médio de filhos por mulher igual a 2.1) têm na redução do volume da

Mário Antônio Sanches, Cleusa Regina Ferreira da Luz, Daiane Priscila Simão-Silva 
população e no seu envelhecimento.

A situação de desigualdade social, política e econômica encontrada no Brasil tem influência direta na estrutura familiar e no número de crianças. Desse modo, os fenômenos demográficos não são independentes do meio no qual se produzem, por isso faz-se necessário investigar as relações que podem existir entre as suas variações e os diversos fatores que exercem influência sobre elas. Pode-se entender que a situação demográfica tem repercussões profundas nos diversos domínios, uma vez que conecta e está conectada em todas as esferas. Entendem-se os indicadores demográficos não somente como consequência, mas também e, principalmente, como causa das políticas demográficas, sociais e econômicas que se desenrolam.

Quanto ao planejamento familiar, o instrumento da pesquisa apresentava a questão: Você planejou a gravidez do seu primeiro filho? e os 655 participantes foram convidados a responder à questão com notas de zero a quatro. $\mathrm{O}$ resultado foi o seguinte: zero - 35,9\%; $1-6,4 \% ; 2-5,0 \% ; 3-8,7 \% ; 4-$ $42,2 \%$, sendo o zero quando não ocorreu planejamento e quatro com ocorrência de planejamento. Se somente $42,2 \%$ atribuíram nota 4 à indagação sobre planejamento familiar, esse número pode ser bem diferente $(7,9 \%)$ para as pessoas que moravam com os pais no momento da gravidez.

Além dos dados demográficos, o planejamento familiar é relevante para a sociedade, pois quando a criança é planejada e recebida com amor e cuidado e contemplada pelos serviços de saúde e educação de qualidade, terá mais chances de se colocar melhor na conjuntura familiar, social e econômica, como argumenta Garrafa:

É natural que um cidadão saudável, escolarizado e treinado tenha melhor possibilidade na disputa de um espaço digno no mercado de trabalho do que outro indivíduo doente, com nenhuma ou pouca escolaridade e sem profissão definida (GARRAFA, 2003, p. 52).

Pensar uma sociedade justa e com igualdade a todos os indivíduos é um grande desafio para qualquer país. Na pesquisa realizada, indagou-se sobre o perfil das famílias no momento da gravidez, com a questão: Com quem você morava quando soube da gravidez do seu primeiro filho? e as respostas foram as seguintes: Sozinho - 1,8\%; Com os amigos - 1,4\%; Com os pais - 17,4\%; Com o(a) parceiro(a) - 72,2; Outro - 5,0\%; NR - 2,1\%. Na Tabela 7, foram cruzadas as respostas com a questão Você planejou a gravidez do seu primeiro filho?, o que revela, coerentemente, o maior índice de nota 4 para a questão $(53,5 \%)$ entre os que moravam com o(a) parceiro(a). No outro extremo, situam-se os que moravam com os pais, dentre os quais $76,3 \%$ atribui nota zero à questão. A partir da análise de correlação, foi possível constatar que o menor número de filhos tem correlação com maior atribuição de planejamento $(\mathrm{r}=-0,081 ; \rho=0,038)$.

Portanto, o quadro do planejamento familiar situa-se também na dinâmica das transformações de configurações familiares. A ausência de planejamento familiar pode ser o reflexo do perfil social dos estados civis, como se constata também nos resultados dos dois últimos censos.

Mário Antônio Sanches, Cleusa Regina Ferreira da Luz, Daiane Priscila Simão-Silva 
Transição Demográfica no Brasil e Planejamento da Parentalidade no

\section{Contexto da Bioética}

Tabela 7 - Dados relacionados: Com quem você morava quando soube da gravidez do primeiro filho? cruzados com Você Planejou a gravidez do seu primeiro filho?

\begin{tabular}{|c|c|c|c|c|c|c|c|c|}
\hline & & \multicolumn{6}{|c|}{ Planejou a gravidez do seu primeiro filho } & \multirow{2}{*}{ Total } \\
\hline $\begin{array}{c}\text { Com quem } \\
\text { morava }\end{array}$ & & zero & 1 & 2 & 3 & 4 & NR & \\
\hline \multirow[t]{2}{*}{ Sozinho } & $\mathrm{N}$ & 8 & 0 & 1 & 0 & 3 & 0 & 12 \\
\hline & $\%$ & $66,7 \%$ & $0,0 \%$ & $8,3 \%$ & $0,0 \%$ & $25,0 \%$ & $0,0 \%$ & $100,0 \%$ \\
\hline Com & $\mathrm{N}$ & 7 & 0 & 1 & 1 & 0 & 0 & 9 \\
\hline os amigos & $\%$ & $77,8 \%$ & $0,0 \%$ & $11,1 \%$ & $11,1 \%$ & $0,0 \%$ & $0,0 \%$ & $100,0 \%$ \\
\hline Com & $\mathrm{N}$ & 87 & 8 & 3 & 6 & 9 & 1 & 114 \\
\hline os pais & $\%$ & $76,3 \%$ & $7,0 \%$ & $2,6 \%$ & $5,3 \%$ & $7,9 \%$ & $0,9 \%$ & $100,0 \%$ \\
\hline Com & $\mathrm{N}$ & 110 & 33 & 24 & 46 & 253 & 7 & 473 \\
\hline parceiro(a) & $\%$ & $23,3 \%$ & $7,0 \%$ & $5,1 \%$ & $9,7 \%$ & $53,5 \%$ & $1,5 \%$ & $100,0 \%$ \\
\hline \multirow[t]{2}{*}{ Outro } & $\mathrm{N}$ & 14 & 1 & 4 & 3 & 10 & 1 & 33 \\
\hline & $\%$ & $42,4 \%$ & $3,0 \%$ & $12,1 \%$ & $9,1 \%$ & $30,0 \%$ & $3,0 \%$ & $100,0 \%$ \\
\hline \multirow[t]{2}{*}{ NR } & $\mathrm{N}$ & 9 & 0 & 0 & 1 & 3 & 1 & 14 \\
\hline & $\%$ & $64,3 \%$ & $0,0 \%$ & $0,0 \%$ & $7,1 \%$ & $21,4 \%$ & $7,1 \%$ & $100,0 \%$ \\
\hline \multirow[t]{2}{*}{ Total } & $\mathrm{N}$ & 235 & 42 & 33 & 57 & 278 & 10 & 655 \\
\hline & $\%$ & $35,9 \%$ & $6,4 \%$ & $5,0 \%$ & $8,7 \%$ & $42,4 \%$ & $1,5 \%$ & $100,0 \%$ \\
\hline
\end{tabular}

Fonte: Os autores (2014).

Os censos de 2000, para 2010, o percentual de pessoas separadas aumentou de $11,9 \%$ para $14,6 \%$. Verificou-se também redução no percentual de pessoas que nunca viveu em união, de 38,6\% para $35,4 \%$. O percentual de pessoas que vivia com o cônjuge passou de 49,5\% em 2000 para 50,1\% em 2010 (IBGE, 2010, s/p).

Na Pesquisa de Planejamento da Parentalidade, o percentual de pessoas que mora com o parceiro foi superior em todas as faixas etárias.

\section{Considerações Finais}

A situação demográfica considerada favorável, por si só, pouco significará se não forem aproveitadas com eficiência, quanto aos meios, e com objetivo social de ampliar, pela qualidade, a capacidade de mobilidade social da maioria da população pobre, reduzindo, desse modo, as desigualdades sociais. Segundo Brito (2008, p. 9):

Mário Antônio Sanches, Cleusa Regina Ferreira da Luz, Daiane Priscila Simão-Silva 
Não há dúvida de que qualquer compromisso com a redução das desigualdades sociais passa, necessariamente, por reforçar na agenda política a necessidade de ações visando ao apoio à população mais pobre, para que tenha condições de regular sua fecundidade.

Esse artigo pretendeu avaliar a associação entre o comportamento populacional à estrutura social, pois os seres humanos caracterizados pela reflexividade de suas ações constituem um sistema complexo e dinâmico, em que a organização social mostra-se capaz de interferir no ordenamento causal das variáveis demográficas. As estratégias quantitativas, sejam elas aplicadas à demografia ou às outras áreas das ciências sociais, apresentam a particularidade de se constituírem de argumentações e reflexões categóricas e sintéticas. Tais variáveis devem ser sintéticas no sentido de descreverem apenas os atributos comuns e regulares presentes em certa população.

De 2000 a 2010, houve aumento das famílias, em que a mulher é responsável, de $22,2 \%$ para $37,3 \%$, respectivamente. Os motivos podem ser creditados a uma mudança de valores relativa ao papel da mulher na sociedade e a fatores como o ingresso maciço no mercado de trabalho e o aumento da escolaridade em nível superior, combinados com a redução da fecundidade, fase que marca o país na transição demográfica e que teve a confirmação nos resultados obtidos por meio da pesquisa de campo do planejamento da parentalidade.

Os desafios do Brasil, nesta fase de transição demográfica, são desenvolver mecanismos para uma expansão demográfica equilibrada entre as mais diversas áreas de seu território e, simultaneamente, cuidar para que as atuais taxas de natalidade sejam efetivamente resultados de um planejamento familiar eficiente, e não apenas consequência de fatores socioeconômicos.

\section{Referências}

ANTOLIN, Rafael Puyol. Geografia humana. 2. ed. Madrid: Pirâmide, 1992.

BANDEIRA, Mário Leston. Teoria de população e modernidade: o caso português. Análise social, v. 31, n. 135, p. 7 - 43, 1996.

BRASIL. Ministério da Saúde. Assistência ao planejamento familiar. Brasília, Secretaria Nacional de Assistência à Saúde, 2011.

BERQUÓ, Elza; CAVENAGUI, Susana. Breve nota sobre a redução no número médio de filhos por mulher no Brasil. Novos Estudos - Fecundidade em Declínio, n. 74, p. 11 - 15, 2006.

BRITO, Fausto. Transição demográfica e desigualdades sócias no Brasil. Revista Brasileira Estudos de População, v. 25, n. 1, p. 5 - 26, 2008.

CAMARANO, Ana Amélia. Perspectivas para o Cairo+20: como avançar na discussão sobre população e desenvolvimento. Revista Brasileira de Estudos de População, v. 30, n. 2, p. 603 - 608, 2013. 
CARVALHO, José Alberto Magno de; BRITO, Fausto. A demografia brasileira e o declínio da fecundidade no Brasil. Revista Brasileira de Estudos de População, v. 22, n. 2, p. 351 - 369, 2005.

CORDEIRO, Hésio. O Sistema Único de Saúde. Rio de Janeiro: Ayuri, 1991.

CORREIA, Francisco de Assis. A alteridade como critério fundamental e englobante da bioética. In: PESSINI, Léo; BARCHIFONTAINE, Christian de Paul de. Fundamentos da bioética. São Paulo: Paulus, 1996.

FORTES, Paulo Antônio de Carvalho. Como priorizar recursos escassos em países em desenvolvimento. In: GARRAFA, Volnei; PESSINI, Leo. Bioética: poder e injustiça. São Paulo: Edições Loyola, 2003, p. 103 - 112.

GARRAFA, Volnei. Reflexão sobre políticas públicas de saúde à luz da bioética. In: FORTES, Paulo Antônio de Carvalho; ZOBOLI, Elma Lourdes Campos Pavone. Bioética e Saúde Pública. São Paulo: Edições Loyola, 2003, p. $49-62$.

IBGE. Instituto Brasileiro de Geografia e Estatística. Censos Demográficos de 1940, 1950, 1960, 1970, 2000 e 2010. Disponível em: $<$ http://www.ibge.gov.br/home/presidencia/noticias/imprensa/ppts/0000000847 3104122012315727483985.pdf>. Acesso em 20 novembro de 2014.

IBGE. Instituto Brasileiro de Geografia e Estatística. Censo 2010. Disponível em: $<$ http://censo2010.ibge.gov.br/noticiascenso? view $=$ noticia\&id $=1 \&$ idnoticia $=2240 \& \mathrm{t}=$ censo- 2010 -unioesconsensuais-ja-representam-mais-13-casamentos-sao-mais-frequentes $>$. Acesso em 20 novembro de 2014.

LIMA, Nísia Trindade. Caminhos da saúde pública no Brasil. Rio de Janeiro: Fiocruz, 2002.

OLIVEIRA, Luiz Antonio Pinto de; SIMÕES, Celso Cardoso da Silva. O IBGE e as pesquisas populacionais. Revista Brasileira de Estudos da População, v. 22, n. 2, p. 291 - 302, 2005.

PUYOL, Antolin Rafael. Geografia humana. 2. ed. Madrid: Cátedra, 1992.

SANCHES, Mario Antônio. Bioética e Planejamento Familiar. São Paulo: Vozes, 2014.

SANCHES, Mario Antônio. Metaparentalidade: reprodução assistida e bioética. Curitiba. Ave-Maria, 2013.

SANCHES, Mário Antonio; KRUM, Juares Celso; RIGONI, Miguel Fernando; SATO, Edésia de Sousa; SANTOS, Renato Barbosa dos. Planejamento da parentalidade no contexto da bioética: busca de uma nova abordagem para pesquisa. Curitiba: PUCPRess, 2015. 
SATO, Edésia de Sousa. Questões socioeconômicas: o impacto sobre o planejamento da parentalidade. 2013. Dissertação (Mestrado em Teologia) Pontifícia Universidade Católica do Paraná, Curitiba, 2013.

SILVA, Susana Maria Veleda da. Inovações nas políticas populacionais: o planejamento familiar no Brasil. Revista Electrónica de Geografía y Ciencias Sociales, n. 69, 2000. Disponível em: <http://www.ub.edu/geocrit/sn69-25.htm.>. Acesso em 20 de novembro de 2014.

SILVA, Luiz Jacintho da. O controle das endemias do Brasil e sua história. Ciência e Cultura, n. 1, v. 55, p. 44 - 47, 2003.

SOUZA E SILVA, J. N. de. Investigações sobre os recenseamentos da população geral do Império e de cada província de per si tentados desde os tempos coloniais até hoje. Relatório do Ministério dos Negócios do Império, Anexo D, Rio de Janeiro: Typ. Nacional, 1870. [Reimpresso em edição facsimilada, São Paulo, IPE/USP, 1986]. 